\title{
The efficacy and safety of atogepant for the prophylactic treatment of migraine: evidence from randomized controlled trials
}

\author{
Xinyu Tao ${ }^{1 \dagger}$, Zeya Yan ${ }^{1 \dagger}$, Jiahao Meng ${ }^{1}$, Wei Wang ${ }^{1}$, Qiling Dai ${ }^{1}$, Qiufeng Zhou ${ }^{2}$, Zhifeng Wang ${ }^{3 *}$ and \\ Zhong Wang ${ }^{1 *}$ (D)
}

\begin{abstract}
Background: Migraine is a common neurovascular disorder that has a severe impact on the individual daily life. Atogepant (AGN-241689) is an orally ingested, small-molecule drugs belonging to calcitonin gene-related peptide receptor antagonist, which has been initiated for the prophylactic treatment of migraine. However, there is no comprehensive literature to study the efficacy and safety of atogepant for the treatment of migraine. In this article, we present a meta-analysis of the available studies.

Methods: MEDLINE, Embase, Cochrane Library and ClinicalTrials.gov were searched before October 20, 2021 for any relevant literature. Eventually, three randomized clinical trials (RCTs) with 2,466 patients were included in our study.

Results: We pooled 2,466 patients from 3 RCTs and primary outcome was mean monthly migraine days, the secondary endpoints were monthly headache days, acute medication use days per month and $\geq 50 \%$ reduction in monthly migraine days, baseline to end of trials. It was found that atogepant (10 mg, $30 \mathrm{mg}, 60 \mathrm{mg}$ once a day) led to a significant reduction in monthly migraine days $(P<0.00001, P<0.00001, P=0.007)$, monthly headache days $(P<0.00001$, $P<0.00001, P=0.001)$, and monthly medication use days $(P<0.00001, P<0.00001, P=0.0001)$, and an increase in the proportion of people with $\geq 50 \%$ reduction in monthly migraine days $(P=0.0008, P=0.02, P=0.04)$ in comparison with placebo. Moreover, there were no significant differences $(P>0.05)$ in outcomes of adverse events between atogepant and placebo.
\end{abstract}

Conclusions: Atogepant has shown good efficacy and safety in the prophylactic treatment of migraine, and further studies are expected.

\section{Introductions}

Migraine is a frequently occurring neurovascular disorder featured of unilateral and repetitious attacks of pulsating headaches, which are exacerbated by daily

\footnotetext{
*Correspondence: maisui1976@163.com; wangzhong761@163.com ${ }^{+}$Xinyu Tao and Zeya Yan are contributed equally to this work.

1 Department of Neurosurgery \& Brain and Nerve Research Laboratory,

The First Affiliated Hospital of Soochow University, Suzhou 215006, Jiangsu Province, China

${ }^{3}$ Department of Neurosurgery, The First People's Hospital of Nantong City, Nantong, Jiangsu Province, China

Full list of author information is available at the end of the article
}

activities and may accompanied by systemic symptoms such as nausea, vomiting, photophobia and phonophobia [1], that could affect the patients' ability to perform activities of daily living. Young and middle-aged people are the main population of migraine attack, particularly with a higher prevalence in women [2]. At least 1 billion people worldwide suffered from migraine in their lifetime [3]. Globally, Migraine imposes a significant burden on individuals and society due to the physiological pain, mobility discomfort and the cumulative cost of treatment $[2,4,5]$. original author(s) and the source, provide a link to the Creative Commons licence, and indicate if changes were made. The images or other third party material in this article are included in the article's Creative Commons licence, unless indicated otherwise in a credit line to the material. If material is not included in the article's Creative Commons licence and your intended use is not permitted by statutory regulation or exceeds the permitted use, you will need to obtain permission directly from the copyright holder. To view a copy of this licence, visit http://creativecommons.org/licenses/by/4.0/. The Creative Commons Public Domain Dedication waiver (http://creativeco mmons.org/publicdomain/zero/1.0/) applies to the data made available in this article, unless otherwise stated in a credit line to the data. 
Many classifications have been applied to the division of migraine subtypes. Among these, it is of great significance for the health management strategies of patients to distinguish between the episodic and chronic forms of this disease. According to The International Classification of Headache Disorders, 3rd edition, episodic migraine (EM) is referred to the headache occurring on fewer than 15 days per month, lasting 4-72 h every time. Chronic migraine (CM), is defined as a headache that occurs at least 15 days per month, lasts for more than 3 months and has to present migraine characteristics on at least 8 days per month $[6,7]$.

When it comes to the management of migraine, two important aspects are acute treatment and preventive treatment. Acute treatment is essential, which gets interventions during a migraine acute attack to obtain relief. While preventive treatment depends on the frequency and severity of the migraine attack, taking into account the effects of adverse reactions [8]. CM, which may derive from episodic migraine, has a higher rate of disability and worse result of therapy, and is more associated with neurological dysfunction $[7,9]$. According to previous epidemiological studies, about $38 \%$ migraineurs need to be preventively treated, with a view to reduce the frequency of migraine attacks and delay disease progression $[10,11]$.

A variety of medications have been used for the preventive treatment of migraine, but these treatments are not effective enough or not tolerated by some patients [12]. The pharmacological effects of drugs cannot be separated from the study on the pathophysiology of migraine. It is commonly accepted that the pathogenesis of migraine relates to abnormal activation and sensitization of the vascular pathways of the trigeminal nervous system [13]. In recent years, with the discovery that migraine attacks may be related to the provocation action of calcitonin gene-related peptide (CGRP) [14], the drugs relating CGRP ligand and receptor have become a new hotspot for clinical use, especially in the acute treatment of migraine attack, and some of them also have been approved for prophylactic treatment one after another, including several CGRP function-blocking monoclonal antibodies (MAbs), erenumab (the recommended dose is $70 \mathrm{mg}$ or $140 \mathrm{mg}$, two consecutive injections of $70 \mathrm{mg}$, by subcutaneous injection once a month), fremanezumab (subcutaneous injection once a month or once every 3 months), galcanezumab (the initial loading dose is $240 \mathrm{mg}$, two consecutive $120 \mathrm{mg}$, followed by $120 \mathrm{mg}$ per month by subcutaneous injection) and eptinezumab (recommended to be administered $100 \mathrm{mg}$ by intravenous injection every 3 months), etc. [15-20]. Although these MAbs have already been available for the prophylactic treatment of migraine, their subcutaneous or intravenous mode of administration caused a degree of inconvenience to patients.

Other treatments such as antidepressants, anticonvulsants, antihypertensive drugs and onabotulinumtoxinA were also recommended for clinical application, but all drugs mentioned above were originally developed as nonspecific therapies [1,21]. When it comes to this issue, we must refer to the other drugs acting on the CGRP pathway, namely CGRP receptor antagonists (gepants). Unlike the preventive MAbs, gepants are mainly taken in forms of pill, nasal spray, orally disintegrating tablet (ODT) [22]. There are currently 2 gepants including ubrogepant and rimegepant (ODT) approved by the FDA respectively in 2019 and 2020 for acute migraine treatment [22]. Subsequently, rimegepant in tablet form was approved for migraine prevention on May 27, 2021, the only gepant that could be used for both acute and preventive migraine treatment. Atogepant became the second FDA-approved oral gepants for migraine prevention which gained approval on 28 September 2021 in the USA, which is also the first oral drug to be exclusively developed for the preventive treatment of episodic migraine [23]. According to the official instructions, the recommended dose is 10,30 or $60 \mathrm{mg}$ once a day [23]. However, a systematic evaluation for the efficacy and safety of atogepant has not yet been performed. In this regard, we conducted a study to discuss the preventive effects of atogepant at different doses through a meta-analysis.

\section{Methods}

A meta-analysis was conducted in conformity with the Preferred Reporting Items for Systematic Reviews and Meta-Analyses (PRISMA) guidelines. Our study has not been registered.

\section{Search strategy}

We systematically searched MEDLINE, Embase, Cochrane Library database and ClinicalTrials.gov for any relevant clinical trials published before October 20, 2021. Search terms included the following: migraine AND (atogepant OR AGN-241689). The reference lists and discussion sections of the identified studies and meta-analyses were searched for additional studies. After removing duplicate and irrelevant studies, two investigators manually screened each possible article by reading title, abstract, etc., to determine whether the study met the predefined inclusion criteria. Any divarication came to an agreement through enough discussion.

\section{Study selection}

Studies were incorporated into our meta if (a) the type of studyies is RCT; (b) participants are adults, aged 18 to 80 years and diagnosed with migraine for at least 


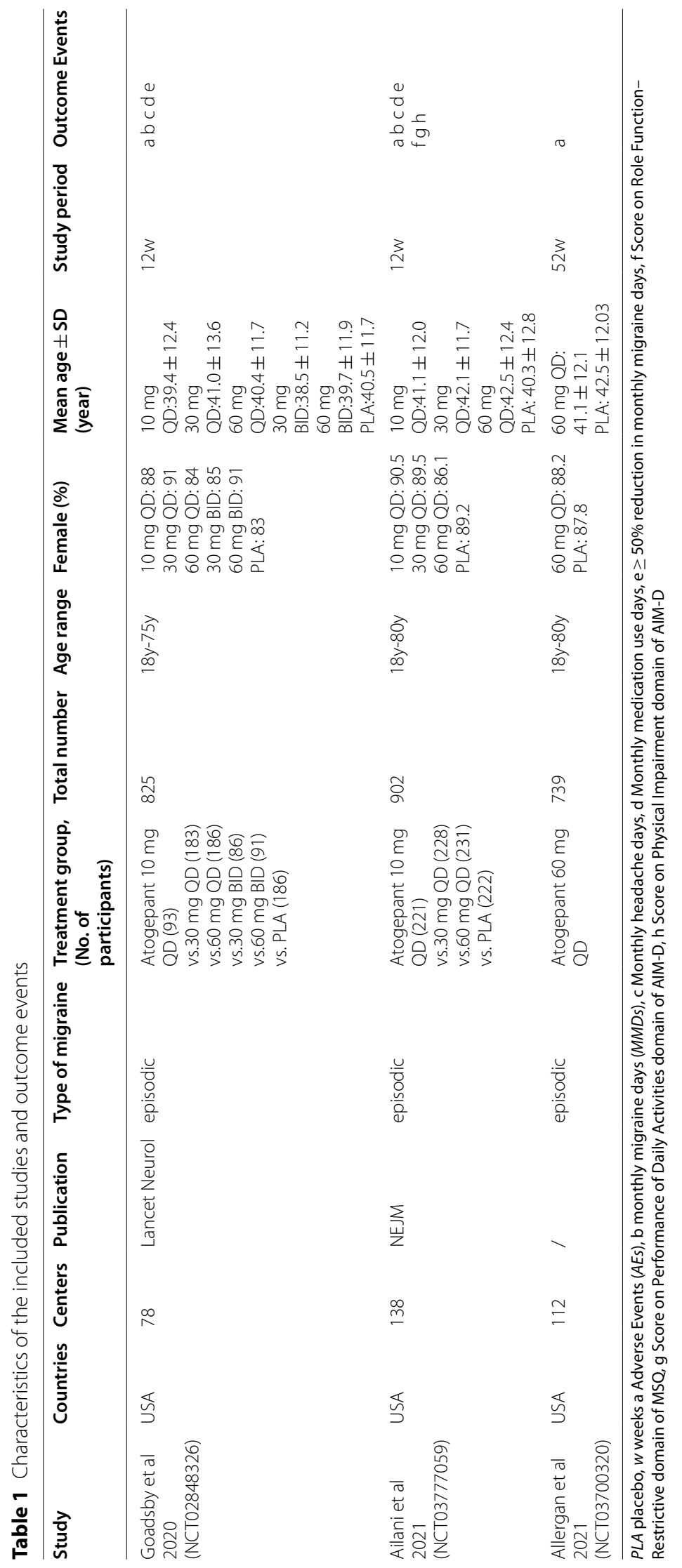


one year; (c) patients had 4 to 14 migraine days monthly before the trials; (d) study used atogepant or placebo as intervention. Studies were excluded if (a) types of study were retrospective studies, cohort studies, and case reports; (b) active control was adopted (namely a known, effective treatment instead of compared with an experimental treatment).

\section{Data extraction}

All the data were extracted independently by 2 investigators (XYT and ZYY) and any disagreements were settled through discussion. After carefully assessing and selecting, the basic information of the included trials (first author, year, number of NCT, countries, centers, publication, type of migraine and treatment group), patient characteristics (age range, mean age and gender), study period and outcome events were used to extract the data (Table 1).

\section{Outcome measures}

The primary efficacy outcome is mean monthly migraine days (MMDs), baseline to the end of trials. Secondary efficacy endpoints included: mean monthly headache days, acute medication use days per month and patients with a $50 \%$ reduction in migraine days from baseline (50\% responder rate). Moreover, the adverse events (AEs) were chosen as the safety endpoint.

\section{Summary measures and synthesis of results}

Review manager 5.4 was used to assess the data. Estimated standard mean differences and estimated risk ratio (standard mean difference [SMD] or risk ratio [RR]; 95\% confidence interval $[\mathrm{CI}]$ ) were calculated using a random effects model. The $I^{2}$ statistic was used to estimate the statistical heterogeneity as follows: $I^{2}<30 \%$ represents "low heterogeneity" $30 \% \leq I^{2} \leq 50 \%$ means "moderate heterogeneity" and $I^{2}>50 \%$ means "substantial

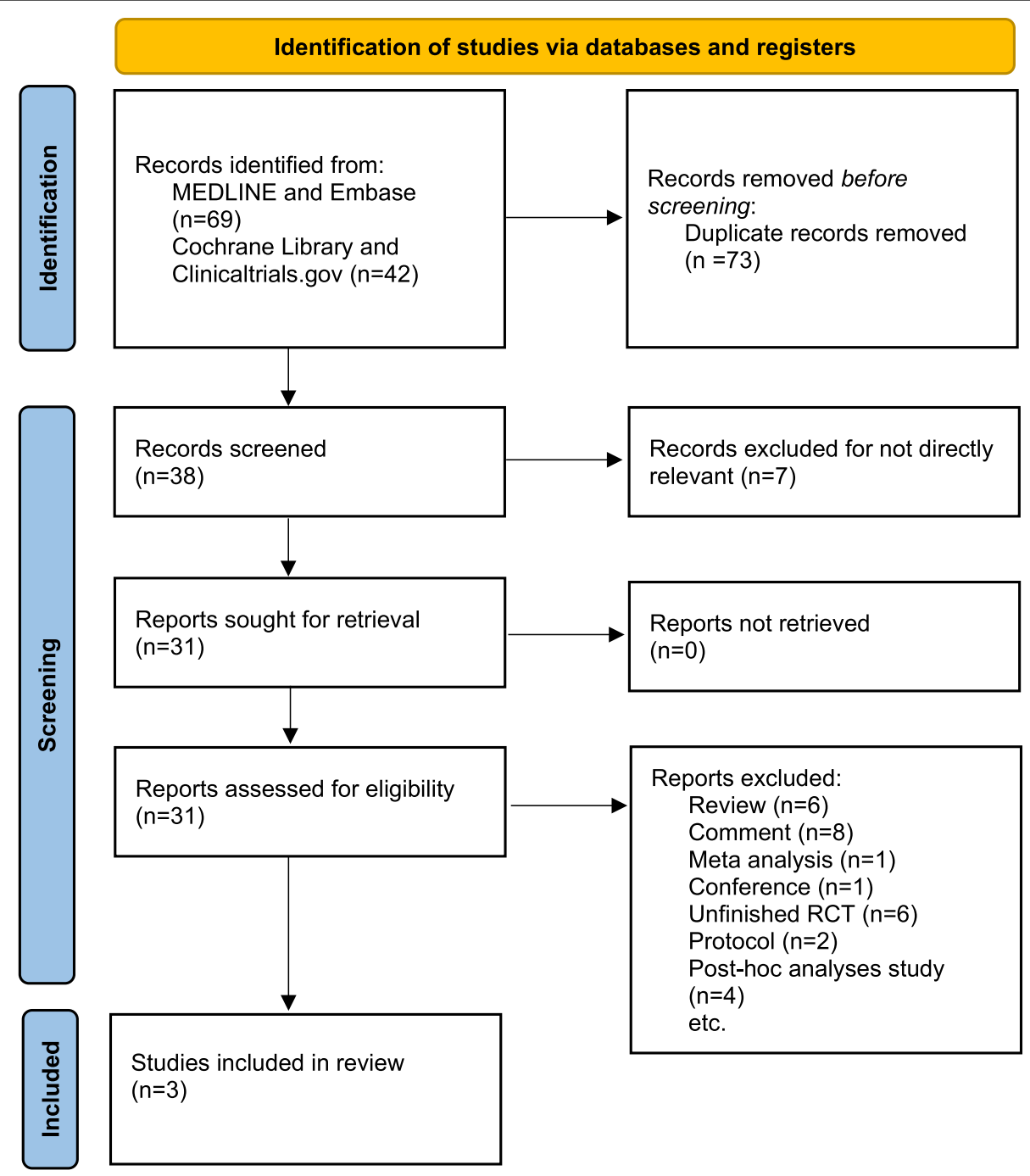

Fig. 1 The study search, selection and inclusion process 


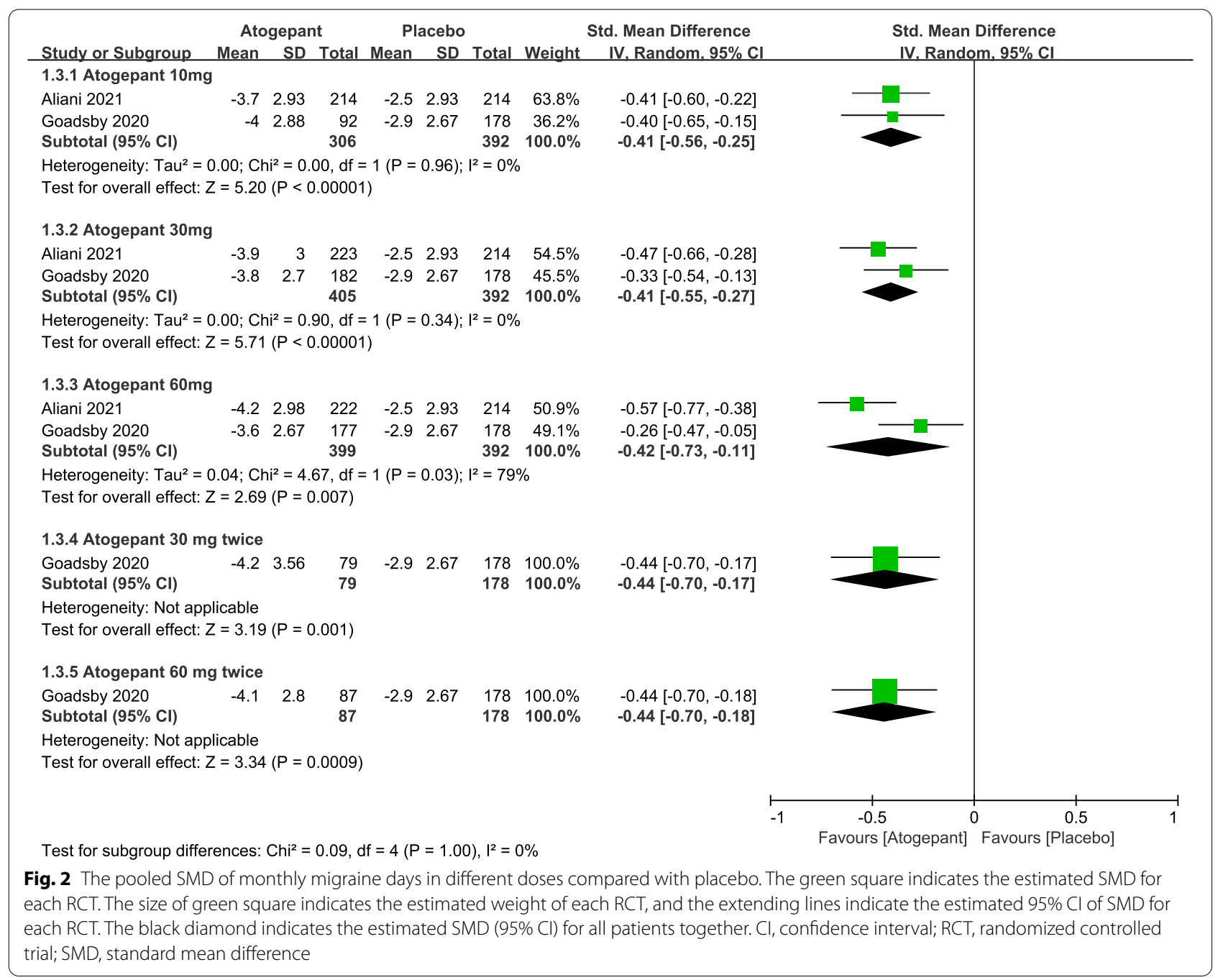

heterogeneity." $P$-value $<0.05$ was considered to be significant for all analyses, and tests are two-tailed.

\section{Risk of Bias}

The risk-of-bias plot was assessed using Review Manager 5.4 software (The Cochrane Collaboration, Oxford, UK) for individual studies. The unified standard of the Cochrane Collaboration was applied to assess the risk of bias for RCTs that included selection bias, performance bias, detection bias, attrition bias, reporting bias, and other potential biases.

\section{Results}

\section{Search results}

Sixty-nine studies and abstracts were retrieved from MEDLINE and Embase, as well as 42 studies from the Cochrane Library and clinicaltrials.gov. 73 studies were removed owing to duplication, and 7 studies were eliminated because they were not directly related to the topic, such as studies of other drugs or pathophysiological study of migraine. After removing duplicates and irrelevant articles, 31 articles were directly related to the topic of interest. However, 28 of these articles were excluded because there were 1 conference, 2 protocol, 4 post-hoc analysis studies, 6 unfinished RCTs, 1 meta-analysis (Interventions are not atogepant versus placebo), $8 \mathrm{com}$ ments and 6 reviews. Eventually, 3 RCTs were included in our study and related information was shown in supplementary materials $\mathrm{S} 1$. The complete search process was detailed in the Fig. 1.

\section{Primary efficacy outcomes}

After measurement, we considered one metric in this study as primary outcomes, namely monthly migraine days (Fig. 2). In terms of this, each of the different doses of atogepant group showed a certain amount of advantages. The mean monthly migraine days during 3 months in the atogepant $10 \mathrm{mg}$ group was 0.41 days less than 


\begin{tabular}{|c|c|c|c|c|c|c|c|c|c|c|}
\hline \multirow[b]{2}{*}{ Study or Subgroup } & \multicolumn{3}{|c|}{ Atogepant } & \multicolumn{2}{|c|}{ Placebo } & & & \multirow{2}{*}{$\begin{array}{l}\text { Std. Mean Difference } \\
\text { IV. Random, } 95 \% \text { CI }\end{array}$} & \multirow{2}{*}{\multicolumn{2}{|c|}{$\begin{array}{l}\text { Std. Mean Difference } \\
\text { IV, Random, } 95 \% \mathrm{Cl}\end{array}$}} \\
\hline & Mean & SD & Total & Mean & & Total & Weight & & & \\
\hline \multicolumn{11}{|c|}{ 2.1.1 Atogepant $10 \mathrm{mg}$} \\
\hline Aliani 2021 & -3.9 & 2.93 & 214 & -2.5 & 2.93 & 214 & $63.5 \%$ & $-0.48[-0.67,-0.28]$ & & \\
\hline Goadsby 2020 & -4.3 & 3.84 & 92 & -2.9 & 4 & 178 & $36.5 \%$ & $-0.35[-0.61,-0.10]$ & & \\
\hline Subtotal $(95 \% \mathrm{Cl})$ & & & 306 & & & 392 & $100.0 \%$ & $-0.43[-0.59,-0.28]$ & & \\
\hline \multicolumn{11}{|c|}{$\begin{array}{l}\text { Heterogeneity: } \mathrm{Tau}^{2}=0.00 ; \mathrm{Chi}^{2}=0.58, \mathrm{df}=1(\mathrm{P}=0.45) ; \mathrm{I}^{2}=0 \% \\
\text { Test for overall effect: } Z=5.53(P<0.00001)\end{array}$} \\
\hline \multicolumn{11}{|c|}{ 2.1.2 Atogepant $30 \mathrm{mg}$} \\
\hline Aliani 2021 & -4 & 3 & 223 & -2.5 & 2.93 & 214 & $52.7 \%$ & $-0.50[-0.70,-0.31]$ & & \\
\hline Goadsby 2020 & -4.2 & 4.05 & 182 & -2.9 & 4 & 178 & $47.3 \%$ & $-0.32[-0.53,-0.11]$ & & \\
\hline Subtotal $(95 \% \mathrm{Cl})$ & & & 405 & & & 392 & $100.0 \%$ & $-0.42[-0.60,-0.24]$ & & \\
\hline \multicolumn{11}{|c|}{ Heterogeneity: $\mathrm{Tau}^{2}=0.01 ; \mathrm{Chi}^{2}=1.61, \mathrm{df}=1(\mathrm{P}=0.20) ; \mathrm{I}^{2}=38 \%$} \\
\hline \multicolumn{11}{|c|}{ Test for overall effect: $Z=4.59(P<0.00001)$} \\
\hline \multicolumn{11}{|c|}{ 2.1.3 Atogepant $60 \mathrm{mg}$} \\
\hline Aliani 2021 & -4.2 & 2.98 & 222 & -2.5 & 2.93 & 214 & $50.9 \%$ & $-0.57[-0.77,-0.38]$ & & \\
\hline Goadsby 2020 & -3.9 & 3.99 & 177 & -2.9 & 4 & 178 & $49.1 \%$ & $-0.25[-0.46,-0.04]$ & & \\
\hline Subtotal $(95 \% \mathrm{Cl})$ & & & 399 & & & 392 & $100.0 \%$ & $-0.41[-0.73,-0.10]$ & & \\
\hline \multirow{2}{*}{\multicolumn{11}{|c|}{$\begin{array}{l}\text { Heterogeneity: } \mathrm{Tau}^{2}=0.04 ; \mathrm{Chi}^{2}=5.03, \mathrm{df}=1(P=0.02) ; \mathrm{I}^{2}=80 \% \\
\text { Test for overall effect: } Z=2.56(P=0.01)\end{array}$}} \\
\hline & & & & & & & & & & \\
\hline \multicolumn{11}{|c|}{ 2.1.4 Atogepant $30 \mathrm{mg}$ twice } \\
\hline Goadsby 2020 & -4.2 & 3.56 & 79 & -2.9 & 4 & 178 & $100.0 \%$ & $-0.33[-0.60,-0.07]$ & & \\
\hline Subtotal $(95 \% \mathrm{Cl})$ & & & 79 & & & 178 & $100.0 \%$ & $-0.33[-0.60,-0.07]$ & & \\
\hline \multicolumn{11}{|c|}{ Heterogeneity: Not applicable } \\
\hline \multicolumn{11}{|c|}{ Test for overall effect: $Z=2.46(P=0.01)$} \\
\hline \multicolumn{11}{|c|}{ 2.1.5 Atogepant $60 \mathrm{mg}$ twice } \\
\hline Goadsby 2020 & -4.3 & 3.73 & 87 & -2.9 & 4 & 178 & $100.0 \%$ & $-0.36[-0.61,-0.10]$ & & \\
\hline Subtotal $(95 \% \mathrm{Cl})$ & & & 87 & & & 178 & $100.0 \%$ & $-0.36[-0.61,-0.10]$ & & \\
\hline \multicolumn{11}{|c|}{ Heterogeneity: Not applicable } \\
\hline \multicolumn{11}{|c|}{ Test for overall effect: $Z=2.71(P=0.007)$} \\
\hline & & & & & & & & & -0.5 & 0.5 \\
\hline \multicolumn{11}{|c|}{ Test for subgroup differences: $\mathrm{Chi}^{2}=0.55, \mathrm{df}=4(\mathrm{P}=0.97), \mathrm{I}^{2}=0 \%$} \\
\hline \multicolumn{11}{|c|}{$\begin{array}{l}\text { Fig. } 3 \text { The pooled SMD of monthly headache days in different doses compared with placebo. The green square indicates the estimated SMD for } \\
\text { each RCT. The size of green square indicates the estimated weight of each RCT, and the extending lines indicate the estimated } 95 \% \mathrm{Cl} \text { of SMD for } \\
\text { each RCT. The black diamond indicates the estimated SMD ( } 95 \% \mathrm{Cl} \text { ) for all patients together. Cl, confidence interval; RCT, randomized controlled } \\
\text { trial; SMD, standard mean difference }\end{array}$} \\
\hline
\end{tabular}

the days in the placebo group $(\mathrm{SMD}=-0.41,95 \% \mathrm{CI}$ : $[-0.56,-0.25], P<0.00001)$, the atogepant $30 \mathrm{mg}$ group $(\mathrm{SMD}=-0.41, \quad 95 \% \mathrm{CI}: \quad[-0.55,-0.27], \quad P<0.00001)$ and the atogepant $60 \mathrm{mg}$ group $(\mathrm{SMD}=-0.42,95 \% \mathrm{CI}$ : $[-0.73,-0.11], P=0.007)$ as well.

\section{Secondary efficacy outcomes}

In this part, a number of endpoint measures were also estimated to explore the efficacy of atogepant for migraine, including monthly headache days, acute medication use days per month and $\geq 50 \%$ reduction in monthly migraine days (Fig. 3, 4 and 5). It revealed that the mean monthly headache days in the atogepant $10 \mathrm{mg}$ $(\mathrm{SMD}=-0.43,95 \% \mathrm{CI}:[-0.59,-0.28], \quad P<0.00001)$, $30 \mathrm{mg} \quad(\mathrm{SMD}=-0.42, \quad 95 \% \mathrm{CI}: \quad[-0.60,-0.24]$, $P<0.00001), 60 \mathrm{mg}$ once-daily groups $(\mathrm{SMD}=-0.41$, 95\%CI: $[-0.73,-0.10], P=0.01)$ were all less than the days in the placebo group. Moreover, the decrease in the average number of days of medication use monthly in 3 months was also an indication of the change in the number of days of migraine attacks and thus confirmed the preventive effect of the drugs. Specific results were as follows: the atogepant $10 \mathrm{mg}$ group $(\mathrm{SMD}=-0.45$, 95\%CI: $\quad[-0.61,-0.30], \quad P<0.00001)$, the atogepant $30 \mathrm{mg}$ group $(\mathrm{SMD}=-0.49,95 \% \mathrm{CI}:[-0.63,-0.35]$, $P<0.00001)$, the atogepant $60 \mathrm{mg}$ group $(\mathrm{SMD}=-0.46$, 95\%CI: $[-0.60,-0.32], P<0.00001)$. In regard to the outcomes of $\geq 50 \%$ reduction in monthly migraine days, the proportion of patients in the atogepant $10 \mathrm{mg}$ group with a $50 \%$ or more reduction in mean migraine days per month during 3 months had a pronounced increase than the placebo group $(\mathrm{RR}=1.66,95 \% \mathrm{CI}$ : $[1.23,2.23]$, $P=0.0008$ ), after that, the same was true for the atogepant $30 \mathrm{mg}$ group $(\mathrm{RR}=1.63,95 \% \mathrm{CI}:[1.07,2.49]$, $P=0.02)$ and the atogepant $60 \mathrm{mg}$ group $(\mathrm{RR}=1.64$, 95\%CI: $[1.01,2.66], P=0.04)$. 


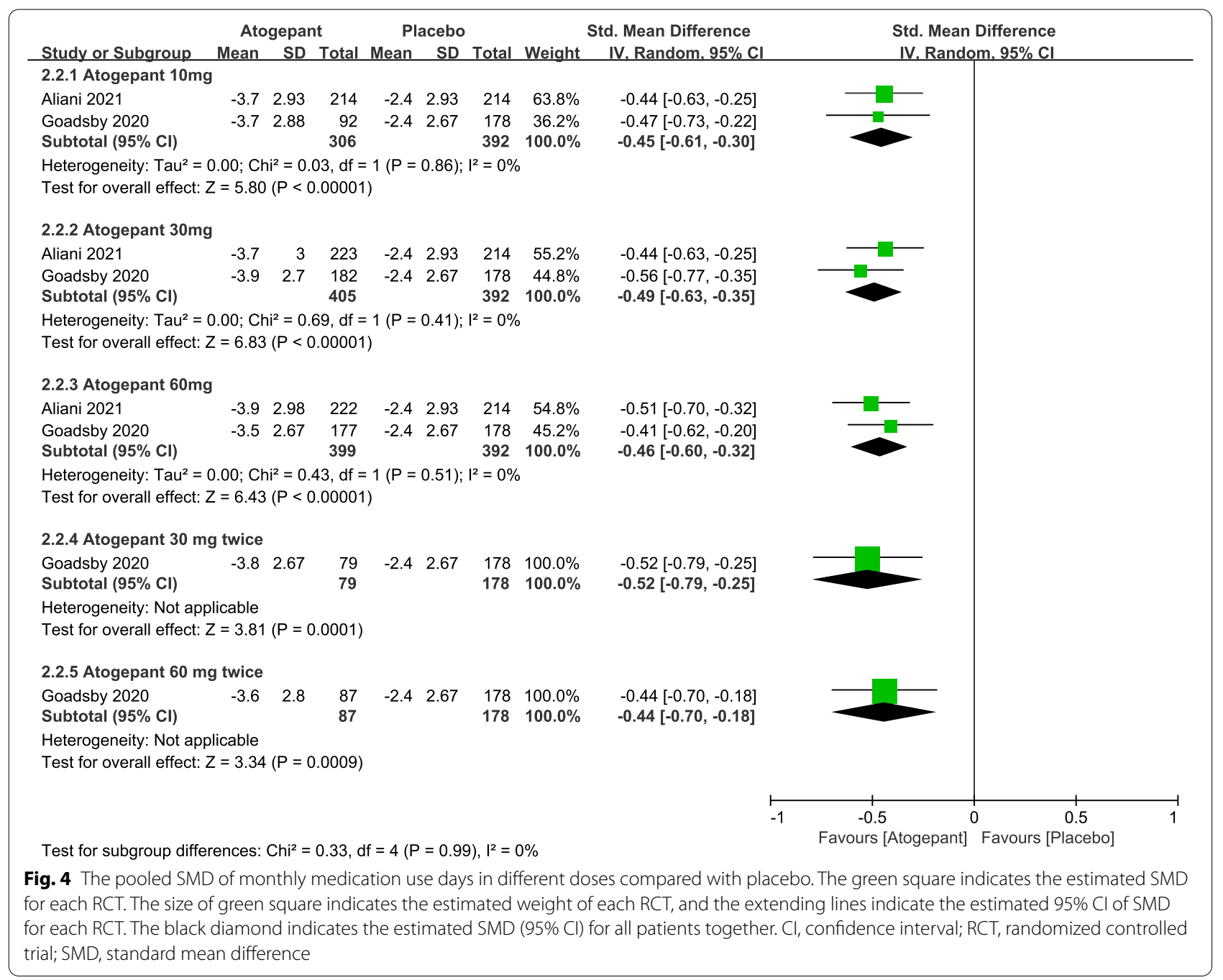

\section{Safety outcomes}

Since the types of adverse events could not be discriminated clearly, only the total number of adverse events was analyzed. As a result, there were no significant differences in outcomes of adverse events between the treatment groups and the placebo group. (atogepant $10 \mathrm{mg}$ : $\mathrm{RR}=1.11,95 \% \mathrm{CI}:[0.78,1.56], P=0.57$, atogepant $30 \mathrm{mg}$ : $\mathrm{RR}=1.08,95 \% \mathrm{CI}:[0.79,1.48], P=0.64$, atogepant $60 \mathrm{mg}$ : $\mathrm{RR}=0.96,95 \% \mathrm{CI}:[0.79,1.17], P=0.68$, Fig. 6).

\section{Subgroup analysis}

We separately conducted a comparative analysis of atogepant $10 \mathrm{mg}$ and $30 \mathrm{mg}, 10 \mathrm{mg}$ and $60 \mathrm{mg}, 30 \mathrm{mg}$ and $60 \mathrm{mg}$ about their efficacy (monthly migraine days, monthly headache days and monthly medication use days) and safety. The results showed that none of the differences in present outcomes (all $p>0.05$ ) (Shown in supplement materials S2 and S3).

\section{Risk of bias}

The independent risk of bias of the three included trials has been appraised with details of Fig. 7. The risks for blinding of outcome assessment (detection bias) are all unclear in the Goadsby et al. 2020 study, Allergan et al. 2021 and Ailani et al. 2021 study. Study conducted by Allergan et al. 2021 had three additional biases that were unclear because the details of the relevant research were not yet available. In addition to the above mentioned, other risks were all low risks of bias in the three trials.

\section{Discussion}

Our study synthetically evaluated the efficacy and safety of atogepant (AGN-241689) which was the newest gepants in nearly 2,466 patients with 4-14 days of migraine per month, including the pivotal Phase $2 \mathrm{~b} / 3$ study (NCT02848326), the Phase 3 placebo-controlled study (NCT03777059) and the Phase 3 safety study (NCT03700320) [24, 25]. These clinical researches have a 


\begin{tabular}{|c|c|c|c|c|c|c|c|c|}
\hline \multirow{2}{*}{$\begin{array}{l}\text { Study or Subgroup } \\
\text { 2.3.1 Atogepant } 10 \mathrm{~m}\end{array}$} & \multicolumn{2}{|c|}{$\begin{array}{l}\text { Atogepant } \\
\text { Events Total }\end{array}$} & $\begin{array}{l}\text { Placebo } \\
\text { Events Total }\end{array}$ & Placebo & Weight & $\begin{array}{l}\text { Risk Ratio } \\
\text { M-H, Random, } 95 \% \mathrm{Cl}\end{array}$ & \multicolumn{2}{|c|}{$\begin{aligned} & \text { Risk Ratio } \\
\mathrm{M}-\mathrm{H}, & \text { Random, } 95 \% \mathrm{Cl}\end{aligned}$} \\
\hline & & & & & & & & \\
\hline Aliani 2021 & 119 & 214 & 62 & 214 & $50.6 \%$ & $1.92[1.51,2.44]$ & & \\
\hline \multirow{2}{*}{$\begin{array}{l}\text { Goadsby } 2020 \\
\text { Subtotal }(95 \% \mathrm{Cl})\end{array}$} & 53 & 92 & 72 & 178 & $49.4 \%$ & $1.42[1.11,1.83]$ & & \\
\hline & & 306 & & 392 & $100.0 \%$ & $1.66[1.23,2.23]$ & & \\
\hline Total events & 172 & & 134 & & & & & \\
\hline \multirow{2}{*}{\multicolumn{9}{|c|}{$\begin{array}{l}\text { Heterogeneity: } \mathrm{Tau}^{2}=0.03 ; \mathrm{Chi}^{2}=2.90, \mathrm{df}=1(P=0.09) ; \mathrm{I}^{2}=65 \% \\
\text { Test for overall effect: } Z=3.34(P=0.0008)\end{array}$}} \\
\hline & & & & & & & & \\
\hline \multicolumn{9}{|l|}{ 2.3.2 Atogepant $30 \mathrm{mg}$} \\
\hline Aliani 2021 & 131 & 223 & 62 & 214 & $49.6 \%$ & $2.03[1.60,2.57]$ & & \\
\hline Goadsby 2020 & 97 & 182 & 72 & 178 & $50.4 \%$ & $1.32[1.05,1.65]$ & & \\
\hline Subtotal $(95 \% \mathrm{Cl})$ & & 405 & & 392 & $100.0 \%$ & $1.63[1.07,2.49]$ & & \\
\hline Total events & 228 & & 134 & & & & & \\
\hline \multicolumn{9}{|c|}{ Heterogeneity: $\mathrm{Tau}^{2}=0.08 ; \mathrm{Chi}^{2}=6.77, \mathrm{df}=1(\mathrm{P}=0.009) ;\left.\right|^{2}=85 \%$} \\
\hline \multicolumn{9}{|c|}{ Test for overall effect: $Z=2.26(P=0.02)$} \\
\hline \multicolumn{9}{|l|}{ 2.3.3 Atogepant $60 \mathrm{mg}$} \\
\hline Aliani 2021 & 135 & 222 & 62 & 214 & $49.8 \%$ & $2.10[1.66,2.65]$ & & \\
\hline Goadsby 2020 & 92 & 177 & 72 & 178 & $50.2 \%$ & $1.28[1.02,1.61]$ & & \\
\hline Subtotal $(95 \% \mathrm{Cl})$ & & 399 & & 392 & $100.0 \%$ & $1.64[1.01,2.66]$ & & \\
\hline Total events & 227 & & 134 & & & & & \\
\hline \multicolumn{9}{|c|}{ Heterogeneity: $\mathrm{Tau}^{2}=0.11 ; \mathrm{Chi}^{2}=8.71, \mathrm{df}=1(\mathrm{P}=0.003) ;\left.\right|^{2}=89 \%$} \\
\hline \multicolumn{9}{|c|}{ Test for overall effect: $Z=2.01(P=0.04)$} \\
\hline \multicolumn{9}{|c|}{ 2.3.4 Atogepant $30 \mathrm{mg}$ twice } \\
\hline Goadsby 2020 & 46 & 79 & 72 & 178 & $100.0 \%$ & $1.44[1.11,1.86]$ & & \\
\hline Subtotal $(95 \% \mathrm{Cl})$ & & 79 & & 178 & $100.0 \%$ & $1.44[1.11,1.86]$ & & \\
\hline Total events & 46 & & 72 & & & & & \\
\hline \multicolumn{9}{|c|}{ Heterogeneity: Not applicable } \\
\hline \multicolumn{9}{|c|}{ Test for overall effect: $Z=2.77(P=0.006)$} \\
\hline \multicolumn{9}{|c|}{ 2.3.5 Atogepant $60 \mathrm{mg}$ twice } \\
\hline Goadsby 2020 & 54 & 87 & 72 & 178 & $100.0 \%$ & $1.53[1.20,1.96]$ & & \\
\hline Subtotal $(95 \% \mathrm{CI})$ & & 87 & & 178 & $100.0 \%$ & $1.53[1.20,1.96]$ & & \\
\hline Total events & 54 & & 72 & & & & & \\
\hline \multirow{2}{*}{\multicolumn{9}{|c|}{$\begin{array}{l}\text { Heterogeneity: Not applicable } \\
\text { Test for overall effect: } Z=3.46(P=0.0005)\end{array}$}} \\
\hline & & & & & & & & \\
\hline & & & & & & $\frac{1}{0.2}$ & 0.5 & 2 \\
\hline \multicolumn{9}{|c|}{ Test for subgroup differences: $\mathrm{Chi}^{2}=0.62, \mathrm{df}=4(\mathrm{P}=0.96), \mathrm{I}^{2}=0 \%$} \\
\hline \multicolumn{9}{|c|}{$\begin{array}{l}\text { Fig. } 5 \text { The pooled RR of } \geq 50 \% \text { reduction in monthly migraine days. The blue square indicates the estimated RR for each RCT. The size of blue } \\
\text { square indicates the estimated weight of each } R C T \text {, and the extending lines indicate the estimated } 95 \% \mathrm{Cl} \text { of RR for each RCT. The black diamond } \\
\text { indicates the estimated RR }(95 \% \mathrm{Cl}) \text { for all patients together. Cl, confidence interval; RCT, randomized controlled trial; RR: risk ratio }\end{array}$} \\
\hline
\end{tabular}

very solid academic significance regarding the evaluation of the safety and efficacy of atogepant for the prevention of episodic migraine. On this basis, it is of great significance to perform a systematic evaluation of research findings to improve the level of evidence for evidencebased medicine. Meta-analysis is high-efficiency study designs, which analyzes a study and its results with predefined steps by definition quantitatively [26]. Until our study, no meta-analysis for atogepant based on clinical trials has been conducted and published. Therefore, our study has some groundbreaking significance and may provide some guidance for the subsequent use of atogepant for migraine treatment.
The results of our meta-analysis showed that atogepant is an effective drug for the prevention of EM, compared with placebo. In the primary outcome, mean number of migraine days per month, all tested doses of atogepant were effective in reducing migraine attacks in patients. In controlled studies of preventive treatment, the percentage of participants with at least a $50 \%$ reduction in the mean number of migraine days per month over three months was recommended as a surrogate primary endpoint [27]. Therefore, we used the mean number of headache days per month, the number of days of acute migraine attack medication use per month, and the number of half remissions as secondary indicators. Consistent 


\begin{tabular}{|c|c|c|c|c|c|c|c|}
\hline & $\begin{array}{l}\text { Atogep } \\
\text { Events }\end{array}$ & $\begin{array}{l}\text { ant } \\
\text { Total }\end{array}$ & $\begin{array}{l}\text { Placeb } \\
\text { Events }\end{array}$ & Total & Weight & \multirow[t]{2}{*}{$\begin{array}{l}\text { Risk Ratio } \\
\text { M-H, Random, } 95 \% \mathrm{Cl}\end{array}$} & $\begin{array}{l}\text { Risk Ratio } \\
\text { M-H, Random, } 95 \% \mathrm{Cl} \\
\end{array}$ \\
\hline \multicolumn{7}{|c|}{ 3.1.1 Atogepant $10 \mathrm{mg}$} & \\
\hline Aliani 2021 & 117 & 221 & 126 & 222 & $51.5 \%$ & $0.93[0.79,1.10]$ & \\
\hline Goadsby 2020 & 61 & 93 & 92 & 186 & $48.5 \%$ & $1.33[1.08,1.63]$ & \\
\hline Subtotal $(95 \% \mathrm{Cl})$ & & 314 & & 408 & $100.0 \%$ & $1.11[0.78,1.56]$ & \\
\hline Total events & 178 & & 218 & & & & \\
\hline \multicolumn{8}{|c|}{$\begin{array}{l}\text { Heterogeneity: } \text { Tau }^{2}=0.05 ; \mathrm{Chi}^{2}=6.69, \mathrm{df}=1(P=0.010) ; \mathrm{I}^{2}=85 \% \\
\text { Test for overall effect: } Z=0.57(P=0.57)\end{array}$} \\
\hline \multicolumn{8}{|c|}{ 3.1.2 Atogepant $30 \mathrm{mg}$} \\
\hline Aliani 2021 & 119 & 228 & 126 & 222 & $50.6 \%$ & $0.92[0.78,1.09]$ & \\
\hline Goadsby 2020 & 115 & 183 & 92 & 186 & $49.4 \%$ & $1.27[1.06,1.53]$ & \\
\hline Subtotal $(95 \% \mathrm{Cl})$ & & 411 & & 408 & $100.0 \%$ & $1.08[0.79,1.48]$ & \\
\hline Total events & 234 & & 218 & & & & \\
\hline \multicolumn{8}{|c|}{ Heterogeneity: $\mathrm{Tau}^{2}=0.04 ; \mathrm{Chi}^{2}=6.46, \mathrm{df}=1(\mathrm{P}=0.01) ;\left.\right|^{2}=85 \%$} \\
\hline \multicolumn{8}{|c|}{ Test for overall effect: $Z=0.47(P=0.64)$} \\
\hline \multicolumn{8}{|l|}{ 3.1.3 Atogepant $60 \mathrm{mg}$} \\
\hline Aliani 2021 & 124 & 231 & 126 & 222 & $34.4 \%$ & $0.95[0.80,1.12]$ & \\
\hline Allergan 2021 & 223 & 543 & 98 & 196 & $33.7 \%$ & $0.81[0.68,0.97]$ & \\
\hline Goadsby 2020 & 107 & 186 & 92 & 186 & $31.9 \%$ & $1.16[0.96,1.41]$ & \\
\hline Subtotal $(95 \% \mathrm{Cl})$ & & 960 & & 604 & $100.0 \%$ & $0.96[0.79,1.17]$ & \\
\hline Total events & 454 & & 316 & & & & \\
\hline Heterogeneity: $\mathrm{Tau}^{2}=$ & .02; $\mathrm{Chi}^{2}$ & $=7.40$, & $\mathrm{df}=2(\mathrm{P}$ & $=0.02$ & $2) ; 1^{2}=73 \%$ & & \\
\hline \multicolumn{8}{|c|}{ Test for overall effect: $Z=0.40(P=0.69)$} \\
\hline \multicolumn{8}{|c|}{ 3.1.4 Atogepant $30 \mathrm{mg}$ twice } \\
\hline Goadsby 2020 & 52 & 86 & 92 & 186 & $100.0 \%$ & $1.22[0.98,1.53]$ & \\
\hline Subtotal $(95 \% \mathrm{Cl})$ & & 86 & & 186 & $100.0 \%$ & $1.22[0.98,1.53]$ & \\
\hline Total events & 52 & & 92 & & & & \\
\hline \multicolumn{8}{|c|}{ Heterogeneity: Not applicable } \\
\hline \multicolumn{8}{|c|}{ Test for overall effect: $Z=1.76(P=0.08)$} \\
\hline \multicolumn{8}{|c|}{ 3.1.5 Atogepant $60 \mathrm{mg}$ twice } \\
\hline Goadsby 2020 & 53 & 91 & 92 & 186 & $100.0 \%$ & $1.18[0.94,1.48]$ & \\
\hline Subtotal $(95 \% \mathrm{Cl})$ & & 91 & & 186 & $100.0 \%$ & $1.18[0.94,1.48]$ & \\
\hline Total events & 53 & & 92 & & & & \\
\hline \multicolumn{8}{|c|}{ Heterogeneity: Not applicable } \\
\hline \multicolumn{8}{|c|}{ Test for overall effect: $Z=1.41(P=0.16)$} \\
\hline $\begin{array}{l}\text { Fig. } 6 \text { The pooled RR of } \\
\text { indicates the estimated } \\
\text { the estimated RR }(95 \% \mathrm{C}\end{array}$ & $\begin{array}{l}50 \% \text { redu } \\
\text { eight of ea } \\
\text { for all pati }\end{array}$ & $\begin{array}{l}\text { Iction in } \\
\text { ch } R C T \text {, }\end{array}$ & $\begin{array}{l}\text { adverse } \\
\text { and the } \\
\text { gether. Cl }\end{array}$ & $\begin{array}{l}\text { events. } \\
\text { extendi } \\
\text { confid }\end{array}$ & $\begin{array}{l}\text { The blue s } \\
\text { ding lines in } \\
\text { dence inter }\end{array}$ & $\begin{array}{l}\text { quare indicates the estima } \\
\text { Idicate the estimated } 95 \% \\
\text { val; RCT, randomized contr }\end{array}$ & $\begin{array}{l}\mathrm{h} \text { RCT. The size of blue square } \\
\text { h } \mathrm{RCT} \text {. The black diamond indicates } \\
\text { isk ratio }\end{array}$ \\
\hline
\end{tabular}

with the results of the underlying study, atogepant did show a significant effect on the prevention of migraine attacks. To our disappointment, significant dose-related changes in efficacy were absent in both the primary and secondary outcomes. In order to further investigate a relatively more appropriate dose, a subgroup analysis was carried out with the comparison between every two groups. Eventually, no significant differences were found. Given that the tolerance and subjective sensation of patients, starting treatment in small doses is probably a choose, in spite of no differences in effectiveness or safety for all doses. Besides, atogepant $30 \mathrm{mg}$ twice daily and $60 \mathrm{mg}$ twice daily also showed corresponding efficacy in the Goadsby et al. 2020 study, but considering that these two doses were not included in the Aliani et al. 2021 study, there may not be a trend to recommend these two doses at this time. Given the integrity of the data, we did not exclude twice-daily doses from this study, but more $\mathrm{RCTs}$ are needed to explore their difference in effect from other doses.

With regard to treatment-related AEs, gastrointestinal symptoms such as nausea and constipation are the most common. However, due to the large differences in the types of AEs between the three trials, we were unable to conduct a more detailed analysis. In the overall analysis of all adverse reactions, atogepant showed no significant 


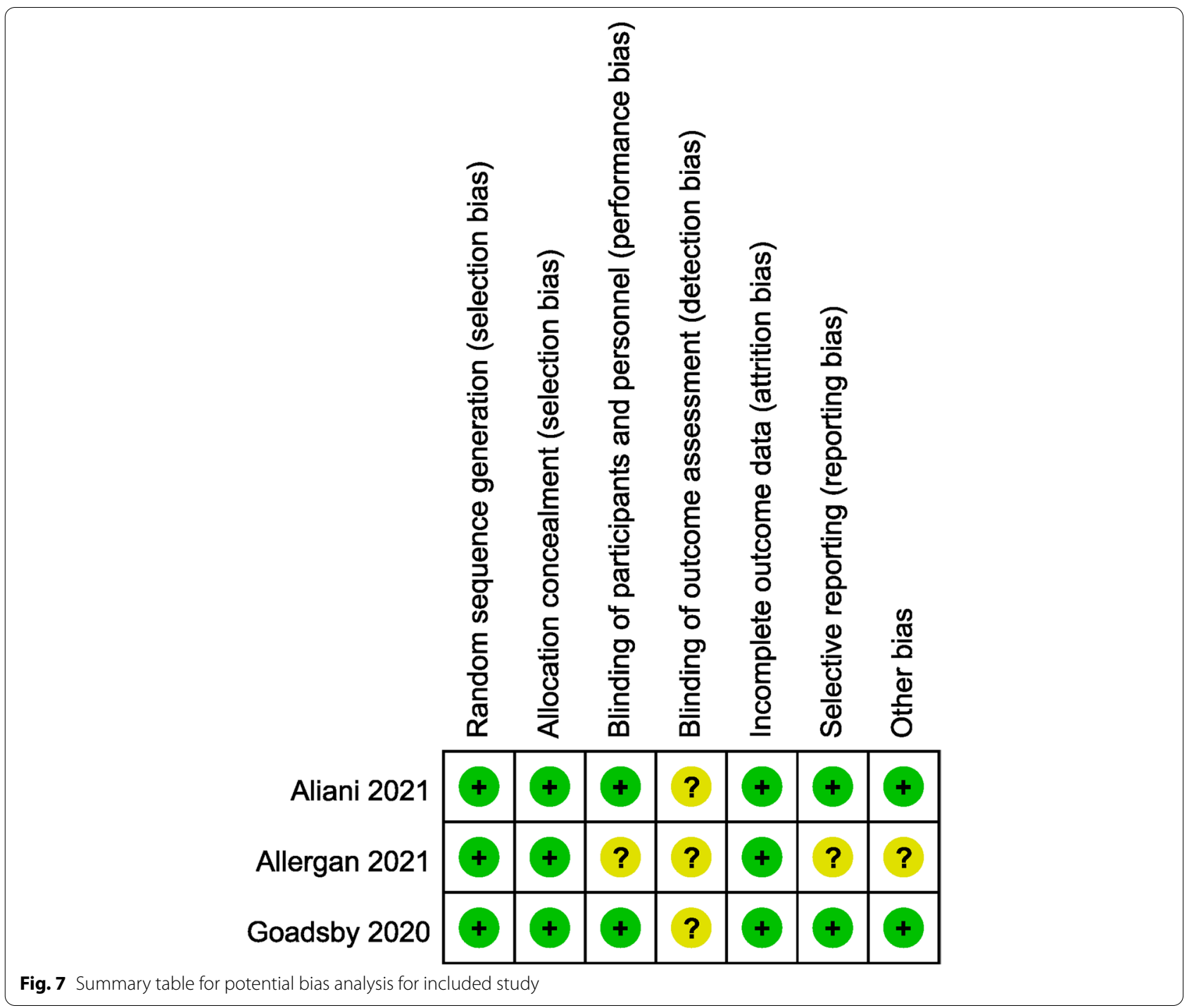

differences. As an additional note, a recent phase 1 clinical study showed that the combination of multiple daily doses of atogepant $60 \mathrm{mg}$ with a single dose of oral contraceptive ethinyl estradiol $0.03 \mathrm{mg} /$ levonorgestrel $0.15 \mathrm{mg}$ was safe in healthy female, and also had good tolerability [28].

With the exception of gepants, CGRP monoclonal antibodies are equally effective in patients with episodic migraine $[29,30]$, used to preventive treatment. Atogepant, however, is an orally administered small molecule that has a much shorter half-life and may have the advantage of being more convenient and acceptable for some specific patients. CGRP monoclonal antibodies are large molecules that usually be administered intravenously or by subcutaneous injection. Because of their long half-life (21-48 days), therapeutic concentrations of CGRP monoclonal antibodies can last 3 months or longer [31], which may become a problem in some patients. According to relevant studies, upper respiratory tract infection was the most common adverse event in CGRP monoclonal antibodies [32]. Pain at the injection site was also a non-negligible problem that caused bad somatic sensations in individuals. This is not a concern with oral gepants. Nevertheless, in terms of dosing frequency, the small molecule Atogepant needs to be taken orally every day, which may not be an advantage for some people, compared to monthly or monthly injections [33]. Rimegepant has a similar situation for migraine prevention with $75 \mathrm{mg}$ administered orally every other day as a recommended dose. Consequently, this all needs to be measured in a more integrated way. 
Atogepant is a second-generation small molecule CGRP receptor antagonist that has recently received FDA-approval, and there is great scope for research on it. Its performance in comparison with several other preventive drugs deserves to be evaluated from the perspectives of efficacy, safety and economic efficiency. Our study further confirms its efficacy and safety for clinical application, which also brings some benefits to patients with episodic migraine requiring prophylactic treatment.

Inevitably, there were some limitations in our study. The number of RCTs included was small, so there is a lack of comprehensive persuasiveness. And each of the RCTs appeared to have been conducted by the same group of researchers, such that the subjectivity of the researchers caused some bias in the results as well. In addition, the population included in this study was only patients with 4-14 days of headache per month, and the efficacy or safety of chronic migraine patients was not considered. Trials of this type are currently underway and could be a direction for future analysis when more details are refined.

\section{Conclusion}

Given all that, atogepant had shown advantageous efficacy in the treatment of episodic migraine regarding all measures from baseline to end of trials. Its safety had also been validated by comparison with placebo. More studies on atogepant are underway and it is believed that it will show unlimited promise in the future for the treatment of migraine.

\section{Supplementary Information}

The online version contains supplementary material available at https://doi. org/10.1186/s10194-022-01391-2.

\section{Additional file 1.}

Additional file 2.

Additional file 3.

\section{Acknowledgements}

Not applicable

\section{Authors' contributions}

ZW was the principal investigators. XYT and ZYY designed the study and developed the analysis plan; JHM and WW analyzed the data and performed the meta-analysis; QLD contributed to the writing of the article. QFZ and ZFW revised the manuscript and polished the language. All authors read and approved the final submitted paper.

\section{Funding}

This work was supported by the Suzhou Health Talents Training Project (GSWS2019002).

\section{Availability of data and materials}

The data that support the findings of this study are available upon request by contacting with the corresponding author. The data are not publicly available due to privacy or ethical restrictions.

\section{Declarations}

Ethics approval and consent to participate

The ethical approval was not required for this type of study.

\section{Competing interest}

The authors state that there are no competing interests between them.

\section{Author details}

${ }^{1}$ Department of Neurosurgery \& Brain and Nerve Research Laboratory, The First Affiliated Hospital of Soochow University, Suzhou 215006, Jiangsu Province, China. ${ }^{2}$ Department of Neurosurgery, Suzhou Ninth People's Hospital, Suzhou, China. ${ }^{3}$ Department of Neurosurgery, The First People's Hospital of Nantong City, Nantong, Jiangsu Province, China.

Received: 8 December 2021 Accepted: 18 January 2022

Published online: 29 January 2022

\section{References}

1. Dodick DW (2018) Migraine. The Lancet 391(10127):1315-1330

2. Feigin VL et al (2019) Global, regional, and national burden of neurological disorders, 1990-2016: a systematic analysis for the Global Burden of Disease Study 2016. The Lancet Neurology 18(5):459-480

3. Vos T et al (2020) Global burden of 369 diseases and injuries in 204 countries and territories, 1990-2019: a systematic analysis for the Global Burden of Disease Study 2019. The Lancet 396(10258):1204-1222

4. Raggi A et al (2012) A systematic review of the psychosocial difficulties relevant to patients with migraine. J Headache Pain 13(8):595-606

5. Buse DC et al (2013) Psychiatric comorbidities of episodic and chronic migraine. J Neurol 260(8):1960-1969

6. Headache Classification Committee of the International Headache Society (IHS) The International Classification of Headache Disorders, 3rd edition. Cephalalgia, 2018. 38(1): p. 1-211

7. Lipton RB, Silberstein SD (2015) Episodic and chronic migraine headache: breaking down barriers to optimal treatment and prevention. Headache 55(Suppl):2

8. VanderPluym JH et al (2021) Acute Treatments for Episodic Migraine in Adults: A Systematic Review and Meta-analysis. JAMA 325(23):2357-2369

9. Aurora SK, Kulthia A, Barrodale PM (2011) Mechanism of Chronic Migraine. Curr Pain Headache Rep 15(1):57-63

10. Silberstein SD et al (2012) Evidence-based guideline update: pharmacologic treatment for episodic migraine prevention in adults: report of the Quality Standards Subcommittee of the American Academy of Neurology and the American Headache Society. Neurology 78(17):1337-1345

11. Cascio Rizzo A et al (2017) Daith Piercing in a Case of Chronic Migraine: A Possible Vagal Modulation. Front Neurol 8:624

12. Winner PK et al (2020) A Randomized Trial to Evaluate OnabotulinumtoxinA for Prevention of Headaches in Adolescents With Chronic Migraine. Headache 60(3):564-575

13. Goadsby PJ et al (2017) Pathophysiology of Migraine: A Disorder of Sensory Processing. Physiol Rev 97(2):553-622

14. Yuan H, Spare NM, Silberstein SD (2019) Targeting CGRP for the Prevention of Migraine and Cluster Headache: A Narrative Review. Headache 59(Suppl 2):20-32

15. Lattanzi S et al (2019) Erenumab for Preventive Treatment of Migraine: A Systematic Review and Meta-Analysis of Efficacy and Safety. Drugs 79(4):417-431

16. Gao B et al (2020) Safety and Efficacy of Fremanezumab for the Prevention of Migraine: A Meta-Analysis From Randomized Controlled Trials. Front Neurol 11:435

17. Silberstein SD, Cohen JM, Yeung PP (2019) Fremanezumab for the preventive treatment of migraine. Expert Opin Biol Ther 19(8):763-771 
18. Frerichs LM, Friedman DI (2021) Galcanezumab for the prevention of migraine. Pain management 11(2):101-112

19. Dhillon S (2020) Eptinezumab: First Approval. Drugs 80(7):733-739

20. Lundbeck. Vyepti (eptinezumab-jjmr): US prescribing Information. 2020. https :// www.lundb eck.com/uploa d/us/files/pdf/Produ cts/Vyept i_PI_US_EN.pdf. Accessed 5 Mar 2020.

21. De Matteis E et al (2020) Targeting CGRP for migraine treatment: mechanisms, antibodies, small molecules, perspectives. Expert Rev Neurother 20(6):627-641

22. Tepper D (2020) Gepants. Headache 60(5):1037-1039

23. Deeks E.D (2021) Atogepant: First Approval. Drugs 82(1):65-70

24. Goadsby PJ, Dodick DW, Ailani J (2020) Safety, tolerability, and efficacy of orally administered atogepant for the prevention of episodic migraine in adults: a double-blind, randomised phase $2 \mathrm{~b} / 3$ trial (vol 19, pg 727, 2020). Lancet Neurol 19(11):E10-E10

25. Ailani J et al (2021) Atogepant for the Preventive Treatment of Migraine. N Engl J Med 385(8):695-706

26. Hernandez A.V, Marti K.M, Roman Y.M (2020) Meta-Analysis. Chest 158(1S):S97-S102

27. Diener HC et al (2020) Guidelines of the International Headache Society for controlled trials of preventive treatment of migraine attacks in episodic migraine in adults. Cephalalgia 40(10):1026-1044

28. Ankrom W et al (2020) Atogepant Has No Clinically Relevant Effects on the Pharmacokinetics of an Ethinyl Estradiol/Levonorgestrel Oral Contraceptive in Healthy Female Participants. J Clin Pharmacol 60(9):1157-1165

29. Dodick DW (2019) CGRP ligand and receptor monoclonal antibodies for migraine prevention: Evidence review and clinical implications. Cephalalgia 39(3):445-458

30. Khan S, Olesen A, Ashina M (2019) CGRP, a target for preventive therapy in migraine and cluster headache: Systematic review of clinical data. Cephalalgia 39(3):374-389

31. Edvinsson L (2018) The CGRP Pathway in Migraine as a Viable Target for Therapies. Headache 58(Suppl 1):33-47

32. Xu D et al (2019) Safety and tolerability of calcitonin-gene-related peptide binding monoclonal antibodies for the prevention of episodic migraine - a meta-analysis of randomized controlled trials. Cephalalgia 39(9):1164-1179

33. Negro A, Martelletti P (2019) Gepants for the treatment of migraine. Expert Opin Investig Drugs 28(6):555-567

\section{Publisher's Note}

Springer Nature remains neutral with regard to jurisdictional claims in published maps and institutional affiliations.

Ready to submit your research? Choose BMC and benefit from:

- fast, convenient online submission

- thorough peer review by experienced researchers in your field

- rapid publication on acceptance

- support for research data, including large and complex data types

- gold Open Access which fosters wider collaboration and increased citations

- maximum visibility for your research: over $100 \mathrm{M}$ website views per year

At BMC, research is always in progress.

Learn more biomedcentral.com/submissions 